\title{
Relationship between Occupational Safety and Health, and staff satisfaction in the Water Service Industry in Kisumu County - Kenya.
}

\author{
${ }^{1}$ Ibrahim Oluoch, ${ }^{2}$ Jared O. H. Ndeda ${ }^{3}$ Paul Njogu, \\ ${ }^{1 \& 3}$ Institute of Energy and Environmental Technology, Jomo Kenyatta University of Agriculture and \\ Technology (JKUAT) P. O. Box 62000-00200 NAIROBI-KENYA \\ ${ }^{2}$ Physics Department, Jomo Kenyatta University of Agriculture and Technology (JKUAT), P.O.Box \\ 62000-00200 NAIROBI-KENYA
}

\begin{abstract}
The study sought to determine the relationship between occupational safety and health, and staff satisfaction in the Kenyan Kisumu County Water Service industry. The study utilized a descriptive research design. The target population consisted of employees of Kisumu Water and Sewerage Company (KIWASCO) and Lake Victoria South Water Service Board (LVSWSB) working in water treatment works, waste water treatment plants and construction sites. From population of 410, Sample size was determined using standard formula by Fisher (1983). Since the population was $<10,000$, the formula by Mugenda \& Mugenda, (2003) was applied and 81 number of Questionnaires used to obtain primary data finally analyzed using quantitative techniques. A simple random sampling was employed to draw the respondents from each site and self-administered semi-structured questionnaire was used to acquire data. The data was analyzed using Statistical Package for Social Sciences version 21. Frequencies and percentages were obtained and correlations done using Spearman's correlation coefficients. On the respondents organizations, majority at 57(75\%) worked at KIWASCO, 12(15.79\%) worked at LVSWSB while the minority at 7(9.21\%) worked at GULF. Preponderance of the respondents at 61(80.3\%) were males while the least at 15(19.7\%) females. Most of the respondents at 28(36.6\%) were between 29-39 years of age while the same number of respondents forming the minority at 24(31.6\%) were both between 18-28 years and 40-50 years of ages. Preponderance of the respondents at 61(80.3\%) had attained college level of education as their highest, 9(11.8\%) attained secondary while the minority at 6(7.9\%) had attained primary level of education as their highest. On the number of years worked for the organization, majority at $27(35.5 \%)$ had worked for 4 years, 24(31.6\%) had worked 1 year, 15(19.7\%) had worked for 3 years while the least number of respondents at $10(13.2 \%)$ had worked for 2 years for their organization. Preponderance of the respondents at 49(64.5\%) stated that water supply was their nature of work, $14(18.4 \%)$ stated construction as their nature of work while the minority at 13(17.1\%) stated waste water as their nature of work. The study analyzed the relationship between occupational safety and health management practices and work environment using Spearman's rho coefficient, $C L=95 \%$. Logistic regression analysis was done to ascertain the relationship between the dependent and the independent variables pulled together but holding the rest constant each time. It was established that there is a significant strong positive relationship between occupational safety and health management practices and the work environment, $r(76)=0.690^{* *} p=0.000$. There is therefore a direct proportionality between occupational safety and health and work environment; hence direct impact on staff perception/ satisfaction that finally affect staff performance in the water sector industry. This study recommends that managements should improve on the occupational safety and health in the workplace. This would improve safety culture and the staff perception on the work environment for optimal productivity in the service sectors
\end{abstract}

Key words: Occupational health, safety, productivity and staff satisfaction.

\subsection{Background}

\section{Introduction}

According to European Agency for Safety and Health at work (2007), the health of adults of working age affects economic and social development. Recent occupational health data indicate that $40 \%-50 \%$, of the world population is exposed to hazardous conditions in the workplace. It is estimated that approximately 250 million occupational accidents occur worldwide each year, with 
335,000 fatalities ILO, (2005) as cited in Thobora \& Thuita, (2015). Hazards at work are in different forms -chemical, physical, biological, psychological and ergonomics. More than $4 \%$ of the world's annual GDP is lost to occupational accidents and disease (ILO, 2001) as cited in Thobora \& Thuita, (2015). Less attention has been given to occupational accidents by injury researchers in Africa.

The healthy workplace concept provides a valuable tool for developing or reinforcing occupational health and safety standards so that conditions continuously improve for the working population. However, a healthy workplace is not only free of hazards, but should provide an environment that is stimulating and satisfying for those who work there. The healthy organization acknowledges all the elements of occupational health and safety in developing policies and programs for the wellbeing of its workers (WHO, 1999).

Abraham Maslow in the hierarchy of needs theory on human motivation used the terms Physiological, Safety, Belongingness and love, Esteem, Self-Actualization and Self -Transcendence needs, to describe the patterns that human motivations generally move through. This study employs the theory of hierarchy of needs on Safety. Safety at work ranks as an important factor in job satisfaction (Kreitner, 2007; Thobora \& Thuita, 2015).

Nzuve and Ayubu, (2012) explained that Occupational Safety and Health (OSH) has become a global concern for employers, workers and national governments. Despite global efforts to address OSH concerns, it is estimated that 2 million work related fatalities still occur every year. In addition, there are more than 330 million occupational accidents and 160 million work related diseases that affect workers every year (as cited in Ayubu et al., 2012).It is estimated that more than $\$ 1.25$ trillion, which is equivalent to $4 \%$ of the world's Gross Domestic Product (GDP) is lost each year due to occupational accidents and diseases (Ayubu et al.,2012).

In assessment of success factors in the implementation of health and safety programs by Rotich \& Kwasira, (2015); the right to safe and healthy working conditions is part of the broader right of everyone to the enjoyment of just and favorable conditions of work, enshrined inter alia in article 23 of the Universal Declaration of Human Rights and article 7 of the International Covenant on Economic, Social and Cultural Rights.

According to Oxenburgh et al., 2010 (as cited in Katsuro et al., 2010), health and safety of all employees is closely linked to the company's productivity in all workplaces; perception that cases of OSH is largely measured by negative outcomes such as workplace injuries and illness is short of the truth as low incidences of injuries do not necessarily mean adequate safety systems and controls in place. Statistics from Ghana, Kenya, South Africa and Zimbabwe show that, a large proportion of all deaths and morbidities result from accident injuries. In rural District in Kenya, 17\% of all deaths among persons of ages 15-64 years in the 1980s were attributed to injuries (Thobora et al., 2015). The right to safe and healthy working conditions has dramatically gained a lot of interest at the global, regional and national levels (Nzuve et al, 2012). It has been found that occupational safety and health is a multi-disciplinary area that is concerned with the safety, health and welfare of people at the workplace. In addition from the perspective of secondary effect it could protect co-workers, family members, employers, customers, supporters, nearby communities and other members of public affected by workplace environment.

Achievement of the highest standard of safety and health at workplace is critical to eliminate or at least minimize safety and health hazards and risks (as cited in Nzuve et al., 2012). Nyakong'o, (2016); states that the status of occupational health and safety conditions in Kenya is an issue of growing importance to the industrialists, practitioners, the government and consumers at large.

\subsubsection{The occupational Health and Safety Act 2007}

The occupational Safety and Health Act 2007 aims at securing the safety, health and welfare of workers and the protection of persons other than the workers against the risk to safety and health arising out of, or in connection with the activities of persons at work. The Act sets objectives to promote and improve occupational safety and health standards. The OSH services in Kenya are governed by two pieces of legislation: the Occupational Safety and Health Act (OSHA), 2007 and the Work Injury Benefits Act (WIBA), 2007. The purpose of OSHA, 2007 is to secure the safety, health and welfare of people at work, and to protect those not at work from risks to their safety and health arising from, or in connection with, the activities of people at work. The purpose of WIBA, 2007 is to 
provide compensation to employees for work-related injuries and diseases contracted in the course of their employment, and for connected purposes. Nyakang'o (2016) confirms that more than half of the industrial accidents and injuries in Kenya go unreported. The report estimates that occupational health and safety fatalities and injuries in Kenya for the last five years 2000-2004 are: 1528, 1923, 1332, 1599 and 1387, this was viewed from the background that 11,387 factories and other places of work are registered by the Department of Health and Safety. The report observed that in 2003, mining, construction and transport accounted for $41 \%$ of accidents in Kenya, machine operators and assemblers $28 \%$ while other occupations share $31 \%$ of workplace accidents. From this detail, in relation to age groups $44.4 \%$ of the injuries occurred to persons in the age group of 20 to 29 years, $25 \%$ to the age group of 30 to 39 years and $24 \%$ to the age below 20 years. According to Manduku and Munjiri (2017), a closer scrutiny of the OSHA, 2007 reveals that many of the dangerous occurrences and prescribed occupational diseases in the $1^{\text {st }}$ and $2^{\text {nd }}$ schedules may exist. There are several instances of unsafe working conditions and work behavior that both employees and employer should place emphasis on. Assets development and operations of water and sanitation facilities are risky assignments for both contractors and operators.

In the upcoming technology, social conflicts and terrorism; water infrastructure facilities remain vulnerable and easy points of access to implement acts of terror. Despite the role played by these workers in national development, they are exposed to life threatening challenges like poor working conditions/ environments which may lead to safety and health problems. There is need to establish if there is any relationship between management practices and the operations, in both construction sites and water and sanitation facilities. This study therefore sought to establish the relationship between occupational safety and health practices and work environment in the water service industry.

\subsubsection{Work Environment}

According to European Agency for Safety and Health at work, (2007); OSH culture can be described in terms of the informal, cultural aspects of an organization. The latter can have an impact on how OSH is perceived and dealt with, and on whether people are aware of OSH-related issues and act in a safe and healthy way. The term 'safety culture' appears to have been first used after the Chernobyl disaster in 1986. (Taken from Wikipedia, http://en.wikipedia.org/wiki/Chernobyl_disaster. Satisfying work in a safe and pleasant environment is a source of health and well-being; yet the physical, psychological and organizational work environment is all too often responsible for injury and disease. The health of adults of working age affects economic and social development. Recent occupational health data indicate that $40 \%-50 \%$, of the world population is exposed to hazardous conditions in the workplace. It is estimated that approximately 120 million occupational accidents occur worldwide each year, with 200,000 fatalities. Each year between 68 million and 157 million new cases of occupational diseases arise as a consequence of various types of work-related exposures. In addition, approximately $30 \%-50 \%$ of workers in industrialized countries experience psychological stress. Environmental stressors such as hazardous conditions are one cause, but occupational stress results from work organization (e.g. workload, lack of autonomy and control over work, shift work, wage scales and routine, repetitive work). Stress associated with work organization has been shown to contribute to cardiovascular disease, muscular skeletal problems and other conditions. Other than the transfer of unsafe technologies, the changing nature of work will have a dramatic impact on worker's health. Technological innovations will result in job losses, replacement of full time work and parttime work, more work in the informal sector and self-employment. Unfortunately, only 5\%-10\% of workers in developing countries and $20 \%-50 \%$ of workers in industrialized countries have access to adequate occupational health services. In many countries there are neither the resources nor the control of occupational hazards. Healthy workers are more likely to be productive workers, who are essential for successful business and lay the foundation for a prosperous economy and sustainable development. The healthy workplace concept provides a valuable tool for developing or reinforcing occupational health and health standards so that conditions continuously improve for the working population. However, a healthy workplace is not only free of hazards, but also provides an environment that is stimulating and satisfying for those who work there. The healthy organization acknowledges all the elements of occupational health and safety in developing policies and programs 
for the wellbeing of its workers (WHO, 1999).According to Article 42 and 70 Constitution of Kenya, every citizen is guaranteed the right to a clean and healthy environment (Kenya Constitution, 2010). This incorporates the principles of intra-generational and intergenerational equity with regards to the protection of the environment (Kenya Law Report, 2010). This implies that the working environment also needs to be clean and healthy to the workers. In the national report dated $7^{\text {th }}$ April 2011 on migration in the health and social sectors in Kenya, the Public Services International (PSI) observes that a working environment that is rewarding when workers are valued, that is safe and stress free, and that provides satisfying work and opportunities for career development will avoid putting workers in a position to migrate.

The history of OSH in Kenya dates back to 1950, when it was found necessary to have a legal instrument to manage the safety, health and welfare of people employed in factories (ILO,2013). The then colonial government adopted the British Factories Act of 1937. In 1990 the Factories Act was amended to the Factories and Other Places of Work Act, in order to enlarge its scope of coverage. In 2007 this Act was repealed, and was replaced by the Occupational Safety and Health Act (OSHA, 2007). In the same year, the Work Injury Benefits Act was enacted. These laws are administered by the Directorate of Occupational Safety and Health Services (DOSHS). Other legislation that touches on OSH includes the Public Health Act CAP 242, the Environmental Management and Coordination Act (1999), the Radiation Protection Act CAP 243, and the Pest Control Products Act Cap 346. These laws are enforced by different ministries and departments of the Government. According to Wallerstein and Weinger, (1992); three major problems need to be addressed before the field of worker health and safety education can advance: the lack of clarity and consensus on the goals of worker education; lack of standards for effective teaching methods, including the lack of skills in these methods of the people who deliver the trainings and inadequacy of program evaluation. The ILO, 2013 cited the Kenya Economic Survey of 2010 and indicated that the total number of employed persons in Kenya in all sectors in the year 2010 was 10,960,000. The report showed that the number of workplaces in both the formal and informal economies was 140,000, and most of which were micro or small sized enterprises with a low awareness of OSH, and thus were exposing a huge number of workers to workplace risks. According to Peter Thobora and Samuel Thuita, (2015) in assessing the levels of compliance on occupational safety and health risk management practices with occupational safety legislation in public institutions, OSH systems should reduce high level exposures to hazards to ensure safe work environment. This is correct as good systems are just but part of the success in implementation.

Though Rotich and Kwasira, (2015) established a positive, strong and statistically significant relationship between employee training on OHS programs and effective implementation of OHS programs, in assessing success factors in the implementation of occupational health and safety programs in tea firms in Kenya this may not be entirely true as work environment in Kaisugu Tea Factory must have had positive contribution in confirming the significance. In my opinion since PSC is key in effective implementation of OHS programs, the psychosocial aspects of OSH practices and management have greater influence on work environment as indicated by employee satisfaction.

\section{Methodology}

The study utilized a descriptive survey research design. The target populations for this study were 81 number staff working in the clean water treatment, waste water treatment and new project construction sites of LVSWSB and KIWASCO Limited. Descriptive research technique was used as an action strategy to study the current situation in defining the OSH in the water industry. The target population constituted of 60 workers in LVSWSB, 300 in KIWASCO and 50 in Gulf totaling 410 staff. The study used questionnaire, interviews and observation to obtain primary data.

Sample size was determined using a sample size standard formula by Fisher (1983). Since the population was less than 10,000, the formula by Mugenda \& Mugenda, (2003) was applied at a confidence level of $95 \%$ or $1.96 ; p$ is the proportion in the population estimated to have the desired characteristics (estimated at 0.50). $q$ is $1.0-p$ and $d$ is the degree of accuracy desired (set at 0.05).

Authority was secured from both management of LVSWSB and KIWASCO to collect data. Individual participants were sensitized before seeking their consents to freely participate in the research. Questionnaires, observations and photographs were used to collect data. The collected data 
was analyzed using quantitative techniques. Standard deviation to measure response disparity for the Likert -scale question items was also adapted. The entire hypothesis was tested at $95 \%$ confidence level. Descriptive statistics such as frequencies, percentages, mean and standard deviation were used to describe the characteristics of collected data. To meet the objective of this study, research considered OSH awareness and exposure as important aspects of staff satisfaction that impacts directly on productivity. The study conducted a logistic regression analysis to ascertain the relationship between the dependent and the independent variables pulled together but holding the rest constant each time. The study analyzed the relationship between staff awareness of occupational safety and health and work environment using Spearman's rho coefficient, confidence level (CL) = $95 \%$.

\section{Data Analysis And Findings}

\subsection{Demographic Information}

Table 3.1: Demographic Information

\begin{tabular}{|l|l|l|}
\hline Characteristics & Categories & Percentage/Proportion \\
\hline Respondents organization & LVSWSB & $12(15.79 \%)$ \\
\hline & KIWASCO & $57(75.00 \%)$ \\
\hline Gender of the respondent & GULF & $7(9.21 \%)$ \\
\hline & Male & $61(80.3 \%)$ \\
\hline Age of the respondent & Female & $15(19.7 \%)$ \\
\hline & $18-28$ & $24(31.6 \%)$ \\
\hline & $29-39$ & $28(36.8 \%)$ \\
\hline Respondents Highest level of education & $40-50$ & $24(31.6 \%)$ \\
\hline & Primary & $6(7.9 \%)$ \\
\hline & Secondary & $9(11.8 \%)$ \\
\hline Duration worked with organization & College & $61(80.3 \%)$ \\
\hline & One year & $24(31.6 \%)$ \\
\hline & Two years & $10(13.2 \%)$ \\
\hline & Three years & $15(19.7 \%)$ \\
\hline Nature of respondents work & Four years & $27(35.5 \%)$ \\
\hline & Construction & $14(18.4 \%)$ \\
\hline & Water supply & $49(64.5 \%)$ \\
\hline
\end{tabular}

3.2 Relationship between occupational safety and health practices and workplace environment in the water service industry in Kisumu County.

\subsubsection{Relationship between awareness on OSH and Work environment}

The study analyzed the relationship between staff awareness of occupational safety and health and work environment using Spearman's rho coefficient ,Confidence Level (CL) $=95 \%$, It was established that there is a significant moderate positive relationship between staff awareness of occupational safety and health and work environment in the water service industry in Kisumu County $\mathrm{r}(76)=.0363^{* *}, \mathrm{p}=0.001$. This meant that by enhancing awareness among staff on the occupational safety and health, the work environment would become more conducive. This may be confirmed by Bandura (1989) that People tend to select activities and associates from the vast range of possibilities in turns of their acquired preferences and competencies. He confirms that the natural and extrinsic effects of their actions in turn, partly determine their thought, patterns and emotional reactions in workplace.

Table 3.2: Relationship between awareness on OSH and Work environment

\begin{tabular}{|l|l|l|l|l|}
\hline Analysis technique & Variable & Descriptors & OSH Awareness & $\begin{array}{l}\text { Work } \\
\text { Environment }\end{array}$ \\
\hline \multirow{3}{*}{ Spearman's rho } & \multirow{2}{*}{ Awareness OSH } & Correlation Coefficient & 1.000 & $.363^{* * *}$ \\
\cline { 3 - 5 } & & Sig. (2-tailed) &. & .001 \\
\cline { 3 - 5 } & $\mathrm{N}$ & 76 & 76 \\
\cline { 2 - 5 } & \multirow{2}{*}{ Work Environment } & Correlation Coefficient & $.363^{* *}$ & 1.000 \\
\cline { 3 - 5 } & Sig. (2-tailed) & .001 &. \\
\cline { 2 - 4 } & $\mathrm{N}$ & 76 & 76 \\
\hline
\end{tabular}




\subsubsection{Relationship between exposure to hazards and risks, and work environment}

The study analyzed the relationship between exposure to hazards and risks and work environment using Spearman's rho coefficient, $C L=95 \%$.It was established that there is an insignificant weak negative relationship between exposure to hazards and risks and work environment, $\mathrm{r}(76)=-0.095, \mathrm{p}=0.413$. This meant that if the exposure to hazards and risks are reduced then the work environment would improve. Ng'ang'a and others (p. 336) explains the indirect proportionality, that there are aspects of work environment that have the potential of causing immediate and sometimes violent harm to a worker hence affecting performance; these include poorly maintained equipments, unsafe machineries, and exposure to hazardous chemicals among others.

Table 3.3: Relationship between exposure to hazards and risks and work environment

\begin{tabular}{|l|l|l|l|l|}
\hline $\begin{array}{l}\text { Analysis } \\
\text { technique }\end{array}$ & Variable & Descriptors & $\begin{array}{l}\text { Exposure } \\
\text { Hazards\& Risk }\end{array}$ & $\begin{array}{l}\text { Work } \\
\text { Environment }\end{array}$ \\
\hline \multirow{3}{*}{ Spearman's rho } & $\begin{array}{l}\text { Exposure to Hazards \& } \\
\text { Risk }\end{array}$ & Correlation Coefficient & 1.000 & -.095 \\
\cline { 3 - 5 } & & Sig. (2-tailed) &. & .413 \\
\cline { 2 - 4 } & $\mathrm{N}$ & 76 & 76 \\
\cline { 2 - 5 } & \multirow{2}{*}{ Work Environment } & Correlation Coefficient & -.095 & 1.000 \\
\cline { 3 - 5 } & & Sig. (2-tailed) & .413 &. \\
\cline { 2 - 4 } & $\mathrm{N}$ & 76 & 76 \\
\hline
\end{tabular}

\subsubsection{Regression analysis on OSH management practice and Work environment}

The study analyzed the relationship between occupational safety and health management practices and work environment using Spearman's rho coefficient, $C L=95 \%$. It was established that there is a significant strong positive relationship between occupational safety and health management practices and the work environment, $\mathrm{r}(76)=0.690^{* *} \mathrm{p}=0.000$. This meant that if the OSH management practices were strengthened then the work environment would improve. Njuguna (2007) explained that when workers are well motivated they behave safely at workplace, this minimizes the human error that may cause or create unsafe working environment.

Table 3.4: Regression analysis OSH management practice and Work environment

\begin{tabular}{|c|c|c|c|c|}
\hline $\begin{array}{l}\text { Analysis } \\
\text { technique }\end{array}$ & Variable & Descriptors & $\begin{array}{l}\text { OSH } \\
\text { Managemen } \\
\text { t Practices }\end{array}$ & $\begin{array}{l}\text { Work } \\
\text { Environmen } \\
\mathrm{t}\end{array}$ \\
\hline \multirow{6}{*}{$\begin{array}{l}\text { Spearman's } \\
\text { rho }\end{array}$} & \multirow{3}{*}{$\begin{array}{l}\text { OSH } \\
\text { Practices }\end{array}$} & Correlation Coefficient & 1.000 & $.690^{* * *}$ \\
\hline & & Sig. (2-tailed) & & .000 \\
\hline & & $\mathrm{N}$ & 76 & 76 \\
\hline & \multirow[t]{3}{*}{ Work Environment } & Correlation Coefficient & $.690^{* * *}$ & 1.000 \\
\hline & & Sig. (2-tailed) & .000 & \\
\hline & & $\mathrm{N}$ & 76 & 76 \\
\hline
\end{tabular}

It was also established that if the employees are aware of occupation safety and health to a large extent, then they are less likely to perceive their work environment as conducive $\mathrm{OR}=0.862$.

It was found that exposure to hazards and risks to a large extent reduced the likelihood for conducive work environment in the water service industry in Kisumu County, OR=0.581 It was therefore established that practicing occupational safety and health to a large extent would increase the chances of conducive working environment in the water service industry in Kisumu County by $80.056 \%$.

Table 3.5: Regression Analysis

\begin{tabular}{|l|l|l|l|l|l|l|l|}
\hline \multicolumn{2}{|c|}{} & B & S.E. & Wald & Df & Sig. & Exp(B) \\
\hline \multirow{3}{*}{ OSH Management Practices } & 4.383 & 1.105 & 15.737 & 1 & .000 & 80.056 \\
\cline { 2 - 8 } & Awareness OSH & -.149 & .806 & .034 & 1 & .853 & .862 \\
\cline { 2 - 7 } & Exposure to Hazards \& Risk & -.543 & .600 & .818 & 1 & .366 & .581 \\
\cline { 2 - 7 } & Constant & -11.627 & 4.890 & 5.653 & 1 & .017 & .000 \\
\hline \multicolumn{2}{|l|}{} \\
\hline
\end{tabular}




\section{Results And Discussion}

It was established that there is a significant moderate positive relationship between staff awareness of occupational safety and health and work environment in the water service industry in Kisumu County $\mathrm{r}(76)=.0363^{* *}, \mathrm{p}=0.001$. This may be confirmed by Bandura (1989) that People tend to select activities and associates from the vast range of possibilities in turns of their acquired preferences and competencies. He confirms that the natural and extrinsic effects of their actions in turn, partly determine their thought, patterns and emotional reactions in workplace.

The study analyzed the relationship between exposure to hazards and risks and work environment using Spearman's rho coefficient, CL=95\%.It was established that there is an insignificant weak negative relationship between exposure to hazards and risks and work environment, $\mathrm{r}(76)=-0.095, \mathrm{p}=0.413$. This meant that if the exposure to hazards and risks are reduced then the work environment would improve. Ng'ang'a and others (p. 336) explains the indirect proportionality, that there are aspects of work environment that have the potential of causing immediate and sometimes violent harm to a worker hence affecting performance; these include poorly maintained equipments, unsafe machineries, and exposure to hazardous chemicals among others. The relationship between occupational safety and health management practices and work environment using Spearman's rho coefficient, $\mathrm{CL}=95 \%$, indicates a significant strong positive relationship between practices and the work environment, $\mathrm{r}(76)=0.690^{* * *} \mathrm{p}=0.000$. This meant that if the OSH management practices were strengthened then the work environment would improve. Njuguna (2007) explained that when workers are well motivated they behave safely at workplace, this minimizes the human error that may cause or create unsafe working environment. The study confirmed that there is relationship between occupational safety and health practices and work environment due to a relationship between staff awareness of occupational safety and health and work environment.

\section{Conclusion}

Going by the significant strong positive relationship between occupational safety and health management practices and the work environment as indicated in the awareness and exposure to hazards and risks, this research therefore concludes that improved employee satisfaction increases productivity in the water service industry in Kenya.

\section{Recommendations}

The management of the water service industry should further improve on their occupational safety and health management practices. This would improve safety culture and the staff perception on the work environment for optimal productivity. This study's conclusion was drown from general management practices and the impacts of hazards in the working environment. The study never looked into the extent and magnitude of the impacts on productivity in the water service industry. Further researches are necessary to ascertain how each of the practices or each aspect of hazards and risks would impact on productivity in the water sector.

\section{References}

[1] Antonsen, S., Safety Culture: theory, method and improvement, Ashgate Pub Co, Uk, 2009,172

[2] Australian Safety and Compensation Council, National Code of Practice for Induction for Construction Work, 2007.

[3] Bandura,A (1989) Social Cognitive Theory. In R Vasta (Ed) Annals of Child Development. Vol. 6. Six theories of Child Development (pp.1-60). Greenwich, CT JAI Press.

[4] Campbell, A ; All Signs Point to Yes; Literacy's Impact on Workplace Health and Safety, Ottawa; The Conference Board of Canada. 2008

[5] European Agency for Safety and Health at Work. Annual Report 2007. Available online at htt://osha.europa.eu

[6] Economic Survey 2011, Kenya National Bureau of Statistics. Available online at http://www.knbs.or.ke

[7] ILO Conventions. Available online at http://www.ilo.org

[8] ILO, (2013). National Profile on Occupational Safety and Health -Kenya

[9] ILO Code of Practice on Recording and Notification of Occupational Accidents and Diseases (ILO, Geneva, 1996): Available online at http://www.ilo.org

[10] International Corporation Finance, Environmental, Health, and Safety Guidelines for Water and Sanitation, 2007.

[11] James. L,. Choi, C., Ko C., McNeil, K., Minton, K., Wright, A., \& Kim, K. (2008). Organizational and psychosocial climate: A review of theory and research. European Journal of Work and Organizational Psychology, 17, 5-32.

[12] Katsuro, P., Gadzirayi, C. T., Taruwona M \& Mupararano, S. (2010). Impact of Occupational Health and Safety on Worker Productivity; A case of Zimbabwe Food Industry. African Journal of Business Management Volume 4 (13), pp. 2644-2651, 4 October 2010. Available online at http://www.academicjournals.org/AJBM.

[13] Kenya National Bureau of Statistics (2010). The 2009 Kenya Population and Housing Census, Volume 1C. 
[14] Kothari, C. R., (2004). Research methodology. Methods and techniques. (2nd ed). New Delhi: New Age International Publishers.

[15] Kreitner, R. (2007). Management. (10 ${ }^{\text {th }}$ ed.) Boston: Houghton Mifflin company

[16] Larcher P \& Sohail M. (1999). Review of Safety in Construction and Operation for the WS\&S Sector: Part 1, London School of Hygiene \& Tropical Medicine, UK WEDC, Loughborough University, UK.

[17] Laws of Kenya, Kenya Law Reports. Available online at http://www.kenyalaw.org

[18] Law, R., Dollard, M., Tuckey,R., \& Dormann, C. (2011). Psychosocial safety climate as a lead indicator of workplace bullying and harassment, job resources, psychological health and employee engagement. Acid. Anal. Prev, 1-12.

[19] Manduku, M.F., Munjuri, M. (2017). Extent of the Implementation of the Occupational Safety and Health Act 2007 in the Sarova Group of Hotels in Nairobi; International Journal Of History And Research Volume 1, Issue 1, pp 1-17, 2017.

[20] Maslow, A., Lowry, R., \& Maslow, B. (1979). The Journal of A. H. Maslow. California: Brooks/Cole.

[21] Mayhew, C., \& Quinlan, M. (2002). Fordism in the Fast Food Industry; Pervasive Management Control and Occupational Health and Safety Risks for Young temporary workers; Blackwell Publishers Ltd / Editional Board 2002 pp 262-284.

[22] Mugenda, O. M. and Mugenda, A. G. (2003).Research Methods: Quantitative and Qualitative Approaches, Acts Press, Nairobi, Kenya

[23] Ng'ang'a, K., Ngigi P., Siboe I., Ongundo D., Wanyona G.,(2013); Health and Safety Conditions at Construction sites in Nairobi County, Kenya.(pp. 336-342).

[24] Nyakong'o, J.B. (2016).Summary Status of Occupational Health And Safety in Kenya. Workshop on the IUPAC-UNIDO Safety Training Program, Part of the IUPAC Congress in Bejing, on Wednesday, August 17

[25] Nzuve, M. \& Ayubu, B. (2012). The Extent of Compliance with Occupational Safety and Health Regulations at Registered Workplaces in Nairobi. International Journal of $\quad$ Business, Humanities and Technology Vol.2 No.2: (pp 115-119).

[26] Occupational Safety and Health Act, 2007. Kenya Gazette Supplement. No 111(Acts No. 15). Available online at http://www.kenyalaw.org

[27] Rotich, L., Kwasira, J. (2015). Assessment of Success Factors in the Implementation of Occupational Health and Safety Programs in Tea Firms in Kenya: A Case of Kaisugu Tea Factory, International Journal of Economics, Commerce and Management Vol. III, Issue 5, May 2015, (pp. 797-811).

[28] Iavicoli S, Rondinone B, Marinaccio A, Fingerhut M, (2005).Research Priorities in Occupational Safety and Health; A review Article; Industrial Health 2006, 44, 169-178.

[29] Thobora, P., Thuita, S (2015). Assessing the Level of Compliance of Occupational Safety and Health Risk Management Practices with Occupational Safety Legislation in Public TVET Institutions in Nairobi, Kenya, Researchjournalis Journal of Industrial Engineering Vol.1 No.1 May 2015.

[30] Vesely, W.E, Goldberg, F.F, Roberts, H.H, Haasl, R.F. (1981) Fault Tree Hand book. Systems and Reliability Research Office of U.S Nuclear Regulatory Commission, Washington D.C 20555

[31] Wallerstein, N; \& Weinger, M. (1992). Health and Safety Education for Worker Empowerment. American Journal of Industrial Medicine 22: 619-635.

[32] WASREB (2015), Impact Report; Performance Review of Kenya's Water Services Sector 2013-2014, Issue No. 8

[33] Wikipedia, available on http://en.wikipedia.org/wiki/Chernobyl_disaster.

[34] WorkSafeNB, Health \& Safety Orientation Guide for Employees, 2014.

[35] WorkSafe Victoria, Controlling OHS Hazards and Risk. A handbook for workplaces, Edition No.1, November 2007.

[36] World Health Organization. (1999). Regional Guidelines for the Development of Healthy Workplaces. 